\title{
Design studies of inner and outer embedded Permanent Magnet for hybrid electric vehicles
}

\author{
Aravind $\mathrm{CV}^{1,}{ }^{*}$, Ramani Kannan ${ }^{2}$, Heng Jing Lei ${ }^{1}$, Joga Dharma Setiawan ${ }^{3}$ \\ ${ }^{1}$ School of Engineering, Taylor's University, Malaysia 47500 \\ ${ }^{2}$ Department of Electrical and Electronics Engineering, University Teknologi PETRONAS, Malaysia \\ ${ }^{3}$ Diponegro University, Indonesia
}

\begin{abstract}
Hybrid vehicles require high torque for propel, hence permanent Magnet machines are highly suiting for the improvement in the torque density. The paper focus on designing built-in interior permanent magnet (IPM) synchronous machine for hybrid electric drive. With the permanent magnet switched from rotor to stator and the characteristics over a wide range of speed operation is studied. The results obtained though performance analysis shows that at $130 \mathrm{rpm}$ high torque with power peaking at around $900 \mathrm{rpm}$. Both the inner and outer machine are studied using numerical study tool for performance analysis for the application mentioned above. The inner magnet rotor design has provide a better magnetic flux flow due to the larger flux linkage between the permanent magnet and stator pole. Both type of machines are evaluated for torque where the machine with inner magnet provide a higher torque density of $4.94 \%$ as compared to the outer magnet machines.
\end{abstract}

\section{Introduction}

Unlike internal combustion engine (ICE) vehicles, the mechanical losses are converted into heat and dissipate to surrounding which does not practice the concept of energy efficiency [1-2]. Hybrid vehicles operate based on permanent magnet machine where magnetic flux linkage generated from the overlapping of magnetic field between permanent magnet and electromagnet [3]. The brushless permanent magnet DC machines have advantages over other machines such as simpler to maintain, more durable, and compact, less likely to suffer reduction in torque performance. The issues occurred where the fixed magnetic field in the stator could not increase the torque density due to difficulty in controlling the magnetic flux. [4-5]. A new type of design that includes two rotors one inside the machine and the other outer rotor enable applications in future wherein the operating mode is feasible in either simultaneous or independent operations using control techniques. A comparative design analysis using torque density value as evaluation parameter is presented to suiting to a hybrid electric vehicle.

\footnotetext{
* Corresponding author: aravindcv@ieee.org
} 


\section{Research Methodology}

\subsection{Permanent Magnet placed in the Rotor}

Figure 1 (a) - Figure 1(c) shows the hybrid drive brushless single rotor interior permanent magnet machine with permanent magnet placed in rotor which is the conventional model used in the electric vehicle including that of the first generation of Toyota hybrid configurations. It encompasses magnet inside the rotor, bringing disadvantages of mechanical stress and loading effect on the vehicle mass. However, for variable speed motion inner rotor type is recommended which makes it a viable case for the hybrid vehicle with the shape of the magnet optimized in the third generation of vehicle types [6-7].

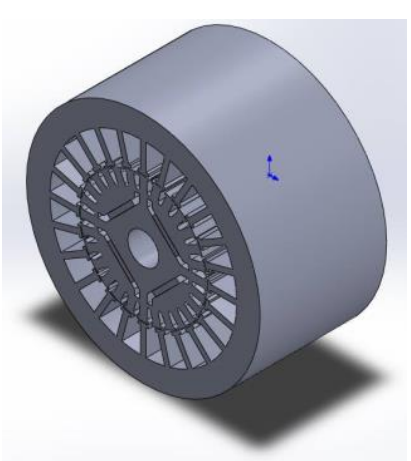

(a) $3 \mathrm{D}$ view.

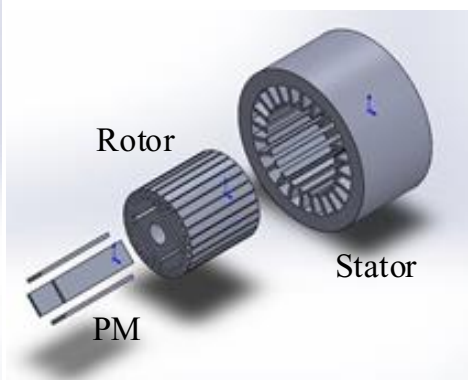

(b) Exploded view.

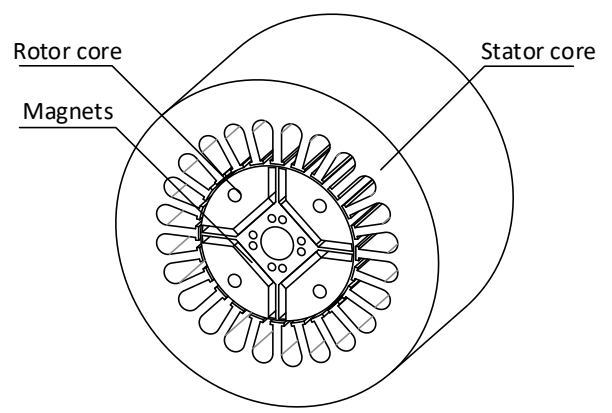

(c) Front view

Fig. 1. Inner permanent magnet motor design.

\subsection{Permanent Magnet placed in the Stator}

The hybrid drive brushless single rotor interior permanent magnet machine with permanent magnet placed in stator is as shown in Figure 2(a) - Figure 2(c) with the rotor light-weight and hence the motion faster. However, the magnetic and the electric loadings in the stator makes it need to be temperature tolerant, which is one of the challenging in this design. But the rotor being less inertia makes it to become faster than that of the motor with inner magnet. 


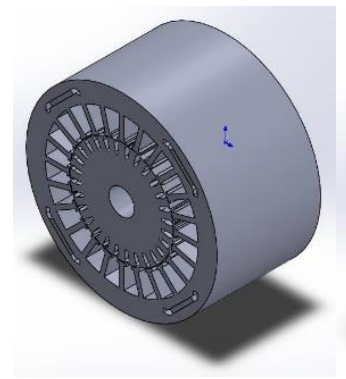

(a) 3D view.

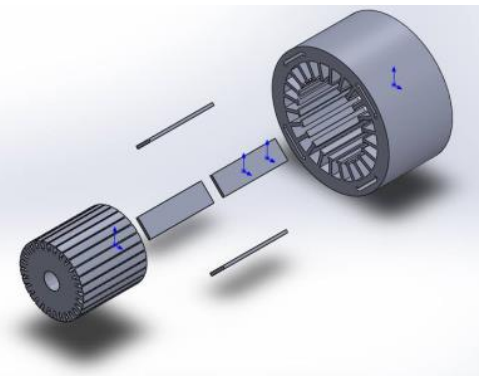

(b) Components.

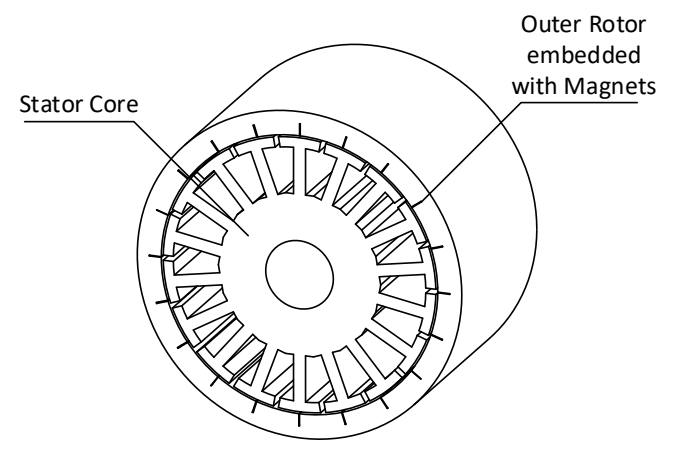

(c) Front view.

Fig. 2. Outer permanent magnet motor design

\section{Design Analysis}

\subsection{Numerical Design}

Finite element analysis simulation used to configure the machine to derive the basic characteristic of the machine that helps to identify the characteristics of the machine before fabrication process. The construction of the machine model done in the beginning by using numerical software tool. In this investigations the models generated are limited to twodimensional and with our previous works [8-11] the results are closer in accuracy with that of the three dimensional model. Figure 3 shows the model machine modeled in $\mathrm{JMAG}^{\circledR}$ software for transient magnetic field analysis.

\subsection{Evaluation Parameters}

In order to evaluate the machine using numerical tools, various performance parameters are utilized for the analysis as in this section.

\subsubsection{Motor Constant $\left(K_{m}\right)$}

Motor constant $\left(K_{m}\right)$ refer to the potential of a machine to convert mechanical power to electrical power and is expressed in Eq. (1), with $I$ being the injected current, $R$ being the resistance of the conductor.

$$
K_{m}=\frac{K_{t}}{\sqrt{I^{2} R}}
$$




\subsubsection{Torque Constant ( $\left.K_{t}\right)$}

Torque constant $\left(K_{t}\right)$ is known as the torque generated $\left(T_{d}\right)$ over the input current $(I)$ is as shown in Eq. (2)

$$
K_{t}=\frac{T_{d}}{I}
$$

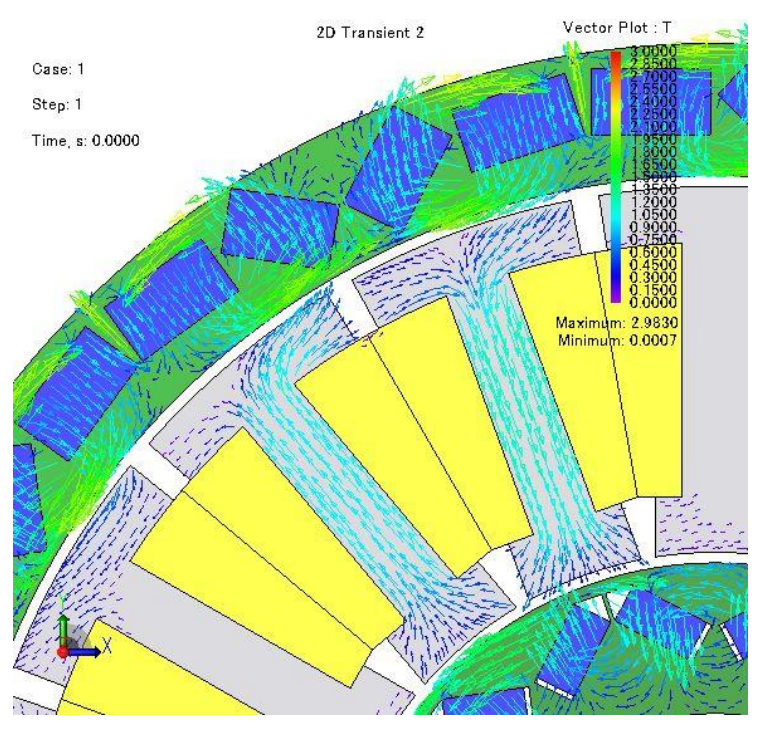

Fig. 3. Flux flow of DRSSPM in FEA tool.

\subsubsection{Torque per Unit Volume $\left(T_{m}\right)$}

Torque per unit volume $\left(T_{m}\right)$ is similar to torque density where it is used as a measure for the torque producing capability of a particular machine. The torque per unit volume is mainly used during the design evaluation stage where the torque density of the mechanical design components can be determined as in Eq. (3), with $L_{s t k}$ the stack length, $D$ is the outer diameter of the machine.

$$
T_{m}=\frac{T_{d}}{\left(\pi D^{2} / 4\right) L_{s t k}}
$$

\subsubsection{Motor Constant Square Density (G)}

Motor constant square density $(G)$, is used to evaluate the overall machine design performance considering the torque, volume, and power of a machine [6-9] as in Eq. (4).

$$
G=\frac{K_{m}^{2}}{\left(\pi D^{2} / 4\right) L_{s t k}}
$$

\section{Results and Discussions}

The starting torque of the machine is the minimal torque required to start the motor, which is $5 \mathrm{Nm}$ as shown in Figure 4, with the torque of the machine seems to drop linearly at the torque above $130 \mathrm{rpm}$. The peak value gives the maximum operating torque the machine 
could develop at the nominal speed. As the speed is increased from the nominal value (the same as power developed is reaching peak) the torque drops (from start-up of the vehicle to reaching constant speed) According to Figure 5, the starting torque of the machine is the minimal torque required to start the motor is approximately $5 \mathrm{Nm}$.

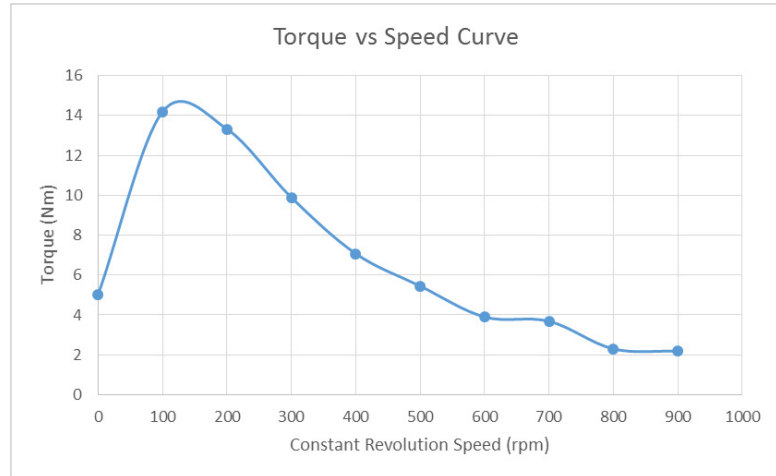

Fig. 4. Torque vs Speed characteristic (outer rotor).

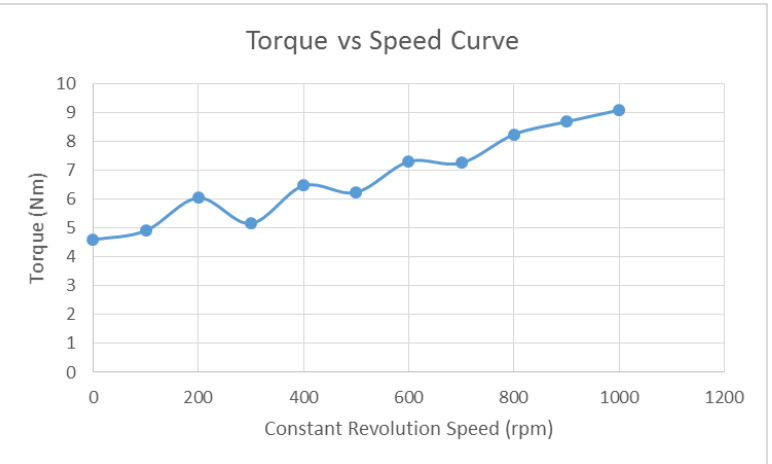

Fig. 5. Torque vs Speed characteristic (inner rotor)

Table 1. Comparative Evaluations

\begin{tabular}{|l|c|c|}
\hline \multicolumn{1}{|c|}{ Parameter } & Outer Magnet & Inner Magnet \\
\hline Current [Amperes] & 15 & 15 \\
\hline Volume $\left[\mathrm{m}^{3}\right]$ & $5.4 \times 10^{-5}$ & $5.4 \times 10^{-5}$ \\
\hline Average Torque $[\mathrm{Nm}]$ & 14.189 & 4.9145 \\
\hline Motor Torque $\left[\mathrm{Nm} / \mathrm{mm}^{3}\right]$ & 409259.26 & 429074.074 \\
\hline Torque Constant $[\mathrm{Nm} / \mathrm{A}]$ & 1.4735 & 1.5449 \\
\hline Motor Constant Square Density & 2851.85 & 2992.59 \\
\hline Improvement in MCSD & - & $4.94 \%$ \\
\hline
\end{tabular}

The torque performance of built-in magnet in rotor machine provide a higher torque performance compared to the modified machine. Inner magnet rotor design provide a better magnetic flux flow and flux linkage between the permanent magnet and stator pole. Both factors have resulted in increasing the torque producing capability of the machine. The inner rotor machine design provides a higher torque to volume ratio performance in 
comparison with that of the outer rotor magnet machine. But the average torque in case of the outer rotor machine is about three times that of the inner motor which makes it suiting for the torque requirement such as the electric and hybrid electric where a high torque density makes the vehicle to run for longer period with the regenerative capability.

\section{Conclusions}

Both inner magnet and outer magnet orientation in interior permanent magnet machine are studied. The machine with inner magnet provide a higher torque density of $4.94 \%$ as compared to the outer magnet machine. Inner magnet rotor design provide a better magnetic flux flow and flux linkage between the permanent magnet and stator pole than that of its counter-part. But the average torque in case of the outer rotor machine is about three times that of the inner motor which makes it suiting for the torque requirement of electric vehicle. This is a promising factor where using magnet in both the stator and the rotor and optimizing it to saturation level might bring new directions of machine design in electric vehicles.

\section{References}

1. X. Zhu, M. Cheng. A Novel Stator Hybrid Excited Doubly Salient Permanent Magnet Brushless Machine for Electric Vehicles, J of Elect. Eng. Tech., 1, 2, 185-191 (2006)

2. C. C. Chan, K. T. Chau, J. Z. Jiang. Vehicles Drives for Electric Vehicles, IEEE Trans. On Indl. Electronics, 43, 2 (1996)

3. Krishnan, Ramu, Switched reluctance motor drives: modeling, simulation, analysis, design, and applications, CRC press, (2001)

4. T. D. Kumar, A. Nagarajan, Design of Switched Reluctance Motor for Elevator Application, J. Asian Sci. Res., 3, 258-267, (2013)

5. Erwan Sulaiman, Takashi Kosaka, Design Improvement and Performance Analysis of 12S-10P Permanent Magnet Flux-Switching Machine with Field Excitation Coil J. E. Sys. 8, 4, 425-432, (2012)

6. Aravind, CV, Lam Pin Wen, Design Evaluations of the New Double Rotor Interior Permanent Magnet Machine, J. Engg. Sci. Tech., Eureca2014, Special Issue, 73-84, (2015)

7. Yee Wan Wong, Lee Wai Chong, Rajparthiban Kumar Rajkumar, Rajprasad Kumar Rajkumar, A New State-of-Charge Estimation Method for Valve Regulated Lead Acid Batteries, J. Engg. Sci. Tech. 12(3), 584-595, (2017)

8. Vaithilingam, C.A, Norhisam M, Zare M.R., Aris.I., Marhaban M.H, Computation of Electromagnetic Torque in a Double Rotor Switched Reluctance Motor Using Energy Methods, Energies, 5, 4008-4026, (2012)

9. Grace I, Aravind CV, Rozita T, Samuel Bright, Optimized Toolbox for the design of Rotary Reluctance Motor,' Proceedings of IEEE Student Conference on Research and Development Conference, Malaysia, doi: 10.1109/STUDENT.2011.6089318, 1-6, (2011)

10. Aravind CV, Norhisam M, Aris.I, Marhaban M.H, M. Nirei, Electromagnetic Design and FEM Analysis of a Novel Dual Air-gap Reluctance Machine, Prog. in Electromagnetic Res., 140, 523-544, (2013)

11. Aravind CV, M. Norhisam, R.N.Firdaus, I. Aris, M. H. Marhaban, Computation of Magnetic Characteristics of the Double Rotor Switched Reluctance Motor using Flux Tube Analysis, J. of Appl. Electro-magnetics and Mech., 21, 3, (2013). 